\title{
002 In Hand: Touch as a Critical Act in Creating and Experiencing the Built Environment
}

\section{David Schafer}

$012-031$

\#architecture

\#craft

\#design

\#digital fabrication

\#hardware
This photo essay depicts the design and fabrication research that David Schafer and his team conducted through a grant from the Association of Siamese Architects (Thailand). His architecture and design practice crafted bespoke objects which investigate the value that hands-on making gives to an intuitive and embodied design. Seeking intimate relationships with the hand, skin, eyes, and body both before, during, and after manifestation, this work describes a material practice intimately familiar with making's feedback mechanisms and constituent benefits to the design studio. They study ergonomic relationships with familiar object typologies and segue into the creation of experientially sensitive door handles in wood, leather, steel, brass, and other materials. The palpable haptic richness of these objects, through a responsive and fertile design process, reveals opportunities amicably distant from standardised, functionalist design methods. 


\section{Introduction: The Future of the Past}

The authors maintain that there is no distinct boundary between the act of design and the act of construction. They are inseparable parts of the same spectrum. The authors prefer to think with their hands and find empirical knowledge to be a critical aspect of our design process.

In our roles as teachers in the classroom and mentors in the studio we see the growing disconnect from architecture as a craft, a separation of thinking from doing, and an increasing abstraction of the Thai designer's education. Architecture schools have no workshops. Designers and students develop ideas solely in digital worlds absent of the texture of material, the vitality of sunlight, and the warmth of a body. Their projects' ambitions are limited to glossy prints. The strong socioeconomic division, and cultural aversion, between the mental and the manual is a particular disservice to the architect whose work is ultimately manifest in unfamiliar techniques and materials known only by name. Increasingly isolated from the act of building, the stifled results are simply retinal exercises. In response, the present research is more concerned with how buildings feel rather than how they look.

We understand the increasing need for specialisation and the growing freedom technology grants. We don't seek to end critical discourse or emphasise practice in the educational environment, but find it necessary to present an alternative form of conception, one that positions the architect as an emphatic maker.

It is perhaps ironic that the digital revolution originated with the fingers on our hands, i.e., counting using our ten digits. The term digital fabrication implies futuristic technologies where the maker is edited out, a utopian design experience where ideas effortlessly come to fruition as the perfect objects designers want them to be. It exalts the absence of the hand, intimating that computer-controlled machines are virtuous and faultless. Designers are simply users and operators, with their role increasingly minimised and mediated. The author and project team believe that fabrication can balance digital processes with the idiosyncratic beauty, sensibilities and temperament of the human. This work does not reject technology. It works to humanise it.

By working with enduring techniques-casting, carving, forming - the project team engage the masters of craft that have preceded them and acknowledge the immaturity of digital fabrication in comparison. In our research, digital fabrication acts similarly to the primitive, and the future reveals itself through actively engaging the past; a synergy between old modes of craft and new modes of production. As digital languages translate to physical machines and actual materials, errors and idiosyncrasies are inevitable. There is a grey area within these glitches. Failure lies at one end and personality lies at the other. Ruskin (1853) saw humanity in the irregularities and errors of Gothic architecture. The work presented identifies and fosters digital glitches in CNC (computer numerical control) processes as humanizing aspects. The project team considers the ghost in the machine to be the ancient soul of the craftsman.

The authors want to immerse their hands back into architecture; to actually touch the structure and details. They want to deeply consider architectural elements of touch, components of a building which directly engage their bodies-door handles, latches, push plates, drawer pulls, handrails, light switches, faucet valves, and toilet levers. They also want to consider their experiences as active participants-pushing, pulling, resting, holding, leaning, and nudging architecture. Furthermore they want to consider the role that these specific points of contact play-enhancing, diminishing, refining, or magnifying their experiences. 
In The Eyes of the Skin, Juhani Pallasmaa writes

the skin reads the texture, weight, density and temperature of matter. The surface of an old object, polished to perfection by the tool of the craftsman and the assiduous hands of its users, seduces the stroking of the hand. It is pleasurable to press a door handle shining from the thousands of hands that have entered the door before us; the clean shimmer of ageless wear has turned into an image of hospitality. The door handle is the handshake of the building. The tactile sense connects us with time and tradition: through impressions of touch we shake the hands of countless generations (Pallasmaa 2005, 56).

\section{Research Methods: Process, Premises, Precepts}

The door can be considered a unifier between spaces. The handle serves as both punctuation to the current space and as an introduction to another, distinct space. Inside to outside. Hallway to bathroom. Bedroom to closet. Street to garden. Crossing the threshold is a physically complex and conceptually rich moment within architecture. We chose to focus on the moment in which passage is initiated, and the micro-site of contact for that act.

This work envisages a door handle engaged in two stages:

The point when one grasps material, we physically understand the form of the handle and subsequently evaluate the feel of the material.

The moment one initiates movement of the handle or latch mechanism we verify our expectations based on our understanding of the discernible design semantics and we experience the physical operation of the instrument.
In addition to readings and photographic surveys, physical prototypes served as the primary modes of investigation for the research shown. The work hybridised analogue and digital processes of making and was conducted within our studio's workshop. We experimented with our own large-scale CNC tooling, and collaborated with Bangkok's network of fabricators and craftsmen.

The work anticipated a concurrent process between fabrication and contextual interpretation. We expected site to inform fabrication, and fabrication to affect our understanding of site. We knew that all forms were derived in the flesh. The computer, through projective digital reality, played a supportive role. All designs were material driven. The work acknowledged and embraced history, use, and wear. We amplified the moment of contact and active engagement of the door handle. The authors encouraged complexity and contradiction. We anticipated that our prototypes would coalesce into a collection of pieces which emphasise process, technique, and material. Read as a whole, these pieces ideally provoke discussion about the friction between the character of the hand and myths of technology.

\section{Research Conclusions: Materials, Methods, Prototypes}

Over several months patterns developed within our ideas and physical sketches. Themes of engagement were organised and refined, sometimes absorbing multiple investigations into a single design. We developed a series of door handles, pulls, and latches that magnify and draw focus to particular physical or experiential moments within the simple act of engaging a door. Four separate approaches, shown through collections, precipitated from the work. 


\section{A. Traces of Wear}

Close contact with the living, breathing, and secreting human body leaves marks and residue that accumulate over time. The touch of the human hand degrades the designer's or manufacturer's vision of finality. We sought materials and finishes that continue to improve over time, aging into graceful weathered patinas, and benefit from the gentle polishing of a repeated touch. The project team derived the form of each handle from hand-lathed wax prototypes. We completed shop drawings digitally.

\section{B. Conduits of Space}

The door handle moves a select portion of wall and connects to the space on the other side. To pre-visualise or pre-engage the other side leads us to reconsider our own space. A peephole allows discreet visual access, helping us to feel secure. Our hand placed on a glass pane helps us brace for the change in weather. The door handle allows for select information to pass through as is appropriate for the relationship of the spaces it connects. We can tune accessories to enrich this complexity. We can reduce a window to the size of a finger, or enlarge a keyhole to the size of a wall.

\section{Expectations of Operation}

An eccentric gear-based mangle rack turns continuous rotational movements into back and forth linear movements. The counterweighted spinning handles intuitively inform the position of the deadbolt throughout the motion, and allude to the tools that were used to manufacture the object itself. Laser cut aluminium plates with hand-turned brass and teak counterweighted knobs add weight to the operation and patina throughout wear.

\section{Fragments of Architecture}

Architecture is an additive process using standard and modular materials. We conceived of door pulls that share the same origins as the building. Working at a small scale with typically largescale materials we established a vocabulary that maintained a faint familiarity, quietly hinting at its origins for those who would listen.

In all cases we desired to add complexity. This initial point of engagement is ripe for opportunity. The door handle as a regulator and interface yearns for intensification. A deeper contemplated object can set the tone or introduce a perspective from which the rest of the space and structure can be understood, like an amuse-bouche. By making strange the typically banal door handle we awaken those who engage in a new sense of what lies beyond (Cadwell 2007). The importance of intimate scale and the tactile engagement places the hand at the origin of this understanding and to the heart of the architecture.

\section{Acknowledgements}

Orapun Sarasalin Schafer, Tongsai Chanta, Krit Chatikavanij, Thiti Kunajitpimol, Sirima Pliencharoen, Supasit Muangsirikul, Panathapon Punjaka, Panumas Dulyasi, Pawimol Samsen, Eric Harman, Linnea Cook. 


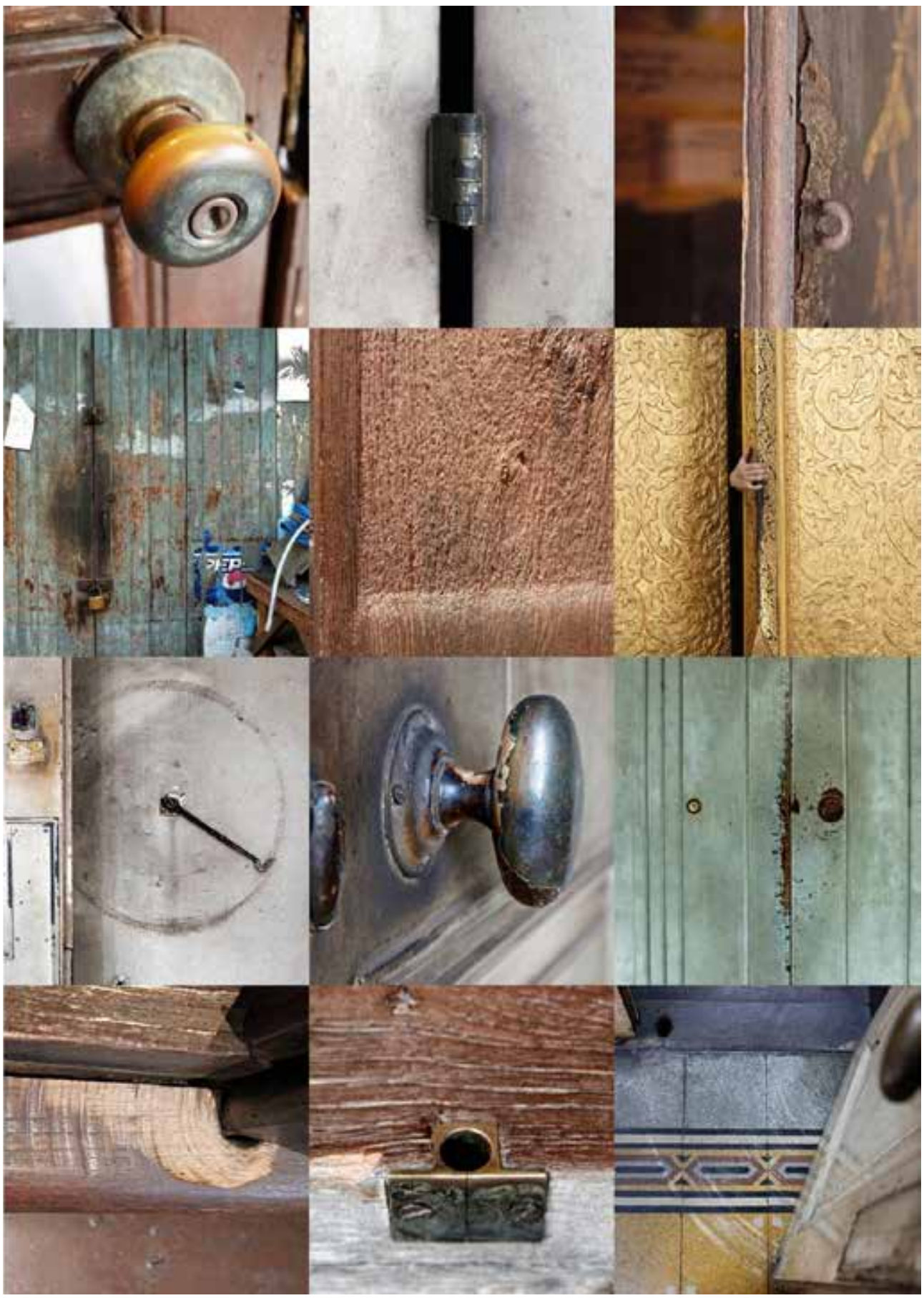

Figure 1: Opening doors and crossing thresholds. Observing old, well-preserved, perfectly neglected architecture, the patterns of wear from both intended and incidental use are conspicuous. The sun, the rains, hands, and movements all leave their marks. Source: author. 


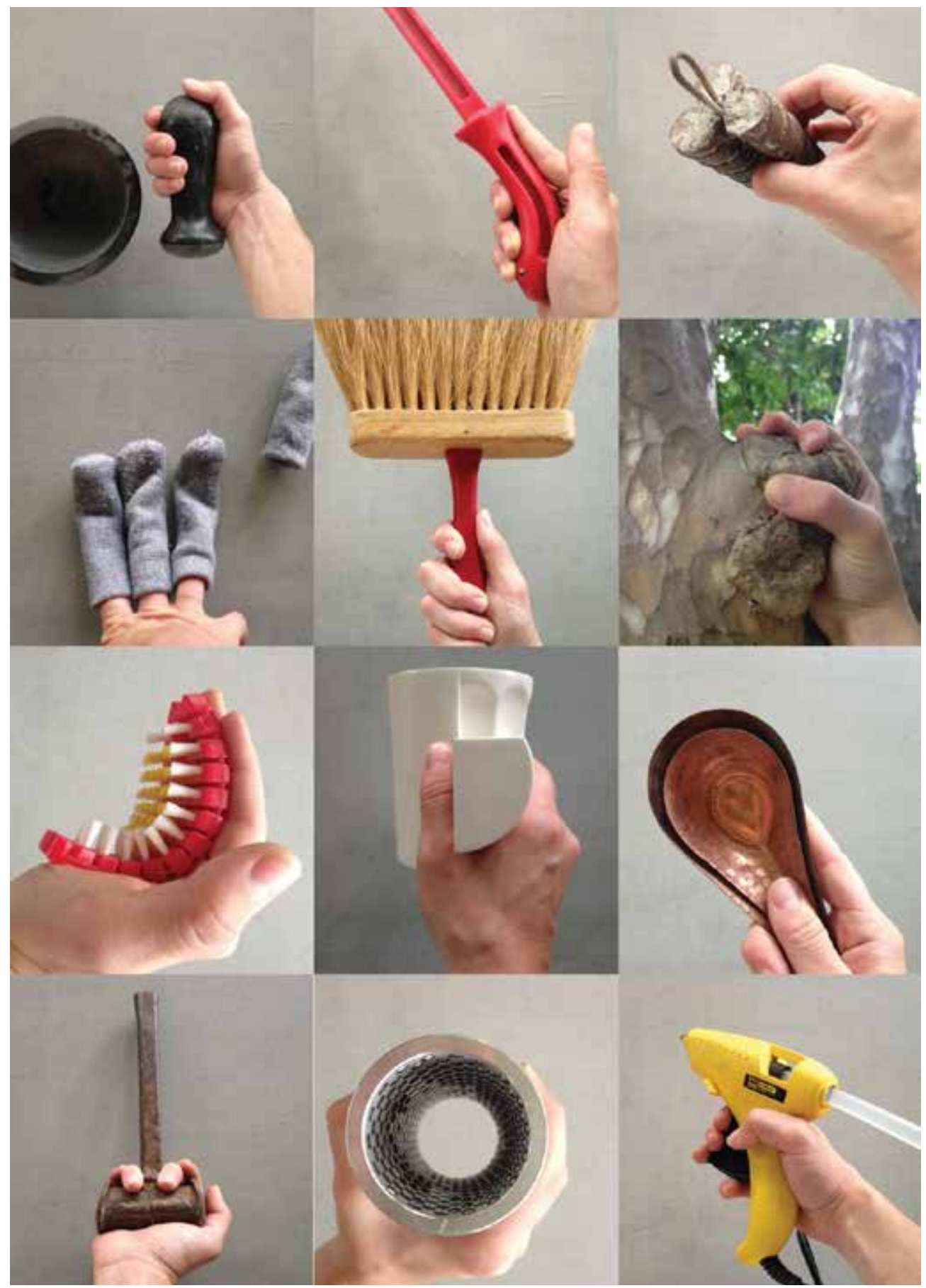

Figure 2: Holding things to see how they feel. In an early exercise we instinctively grasped objects to understand and detect the textures we best respond to, as well as to engage in the visual clues of industrial design semantics, and lastly to allow our hands to settle and discover what we could not see. Source: author. 


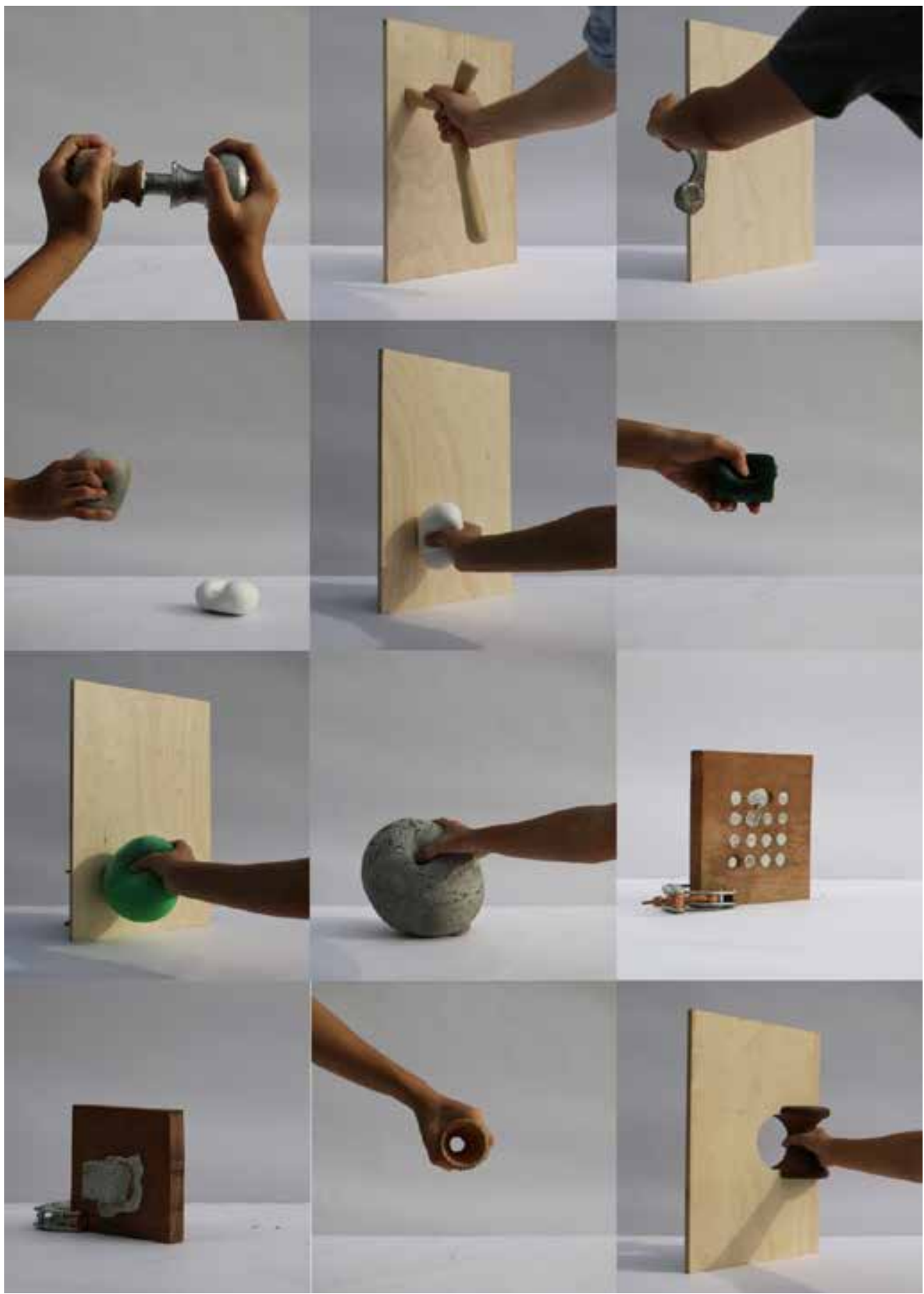

Figure 3: Making sketches that we can touch. Investigations into the use of metals as a conductor, which pre-emptively inform a user of interior conditions. These works use both intuitive forms, and found objects which break from known conventions. As fragments of thresholds, these objects explore engagement of door edges and the penetration of the door surface. Source: author. 


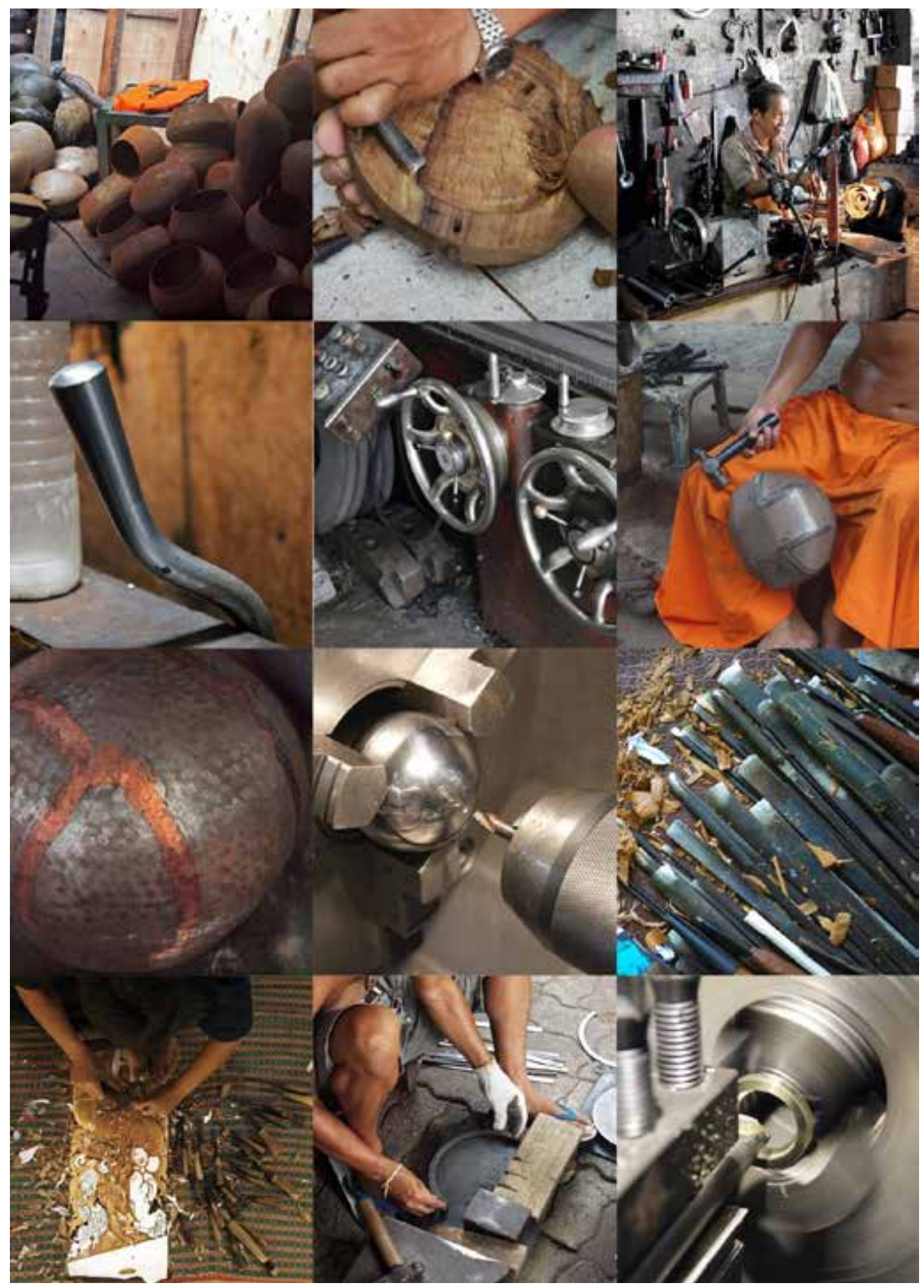

Figure 4: Observing craftsmanship. Workshops and craftsmen help launch our design explorations and material understanding. Our relationship with the makers is as important and complex as our relationship with the materials and techniques. Source: author. 


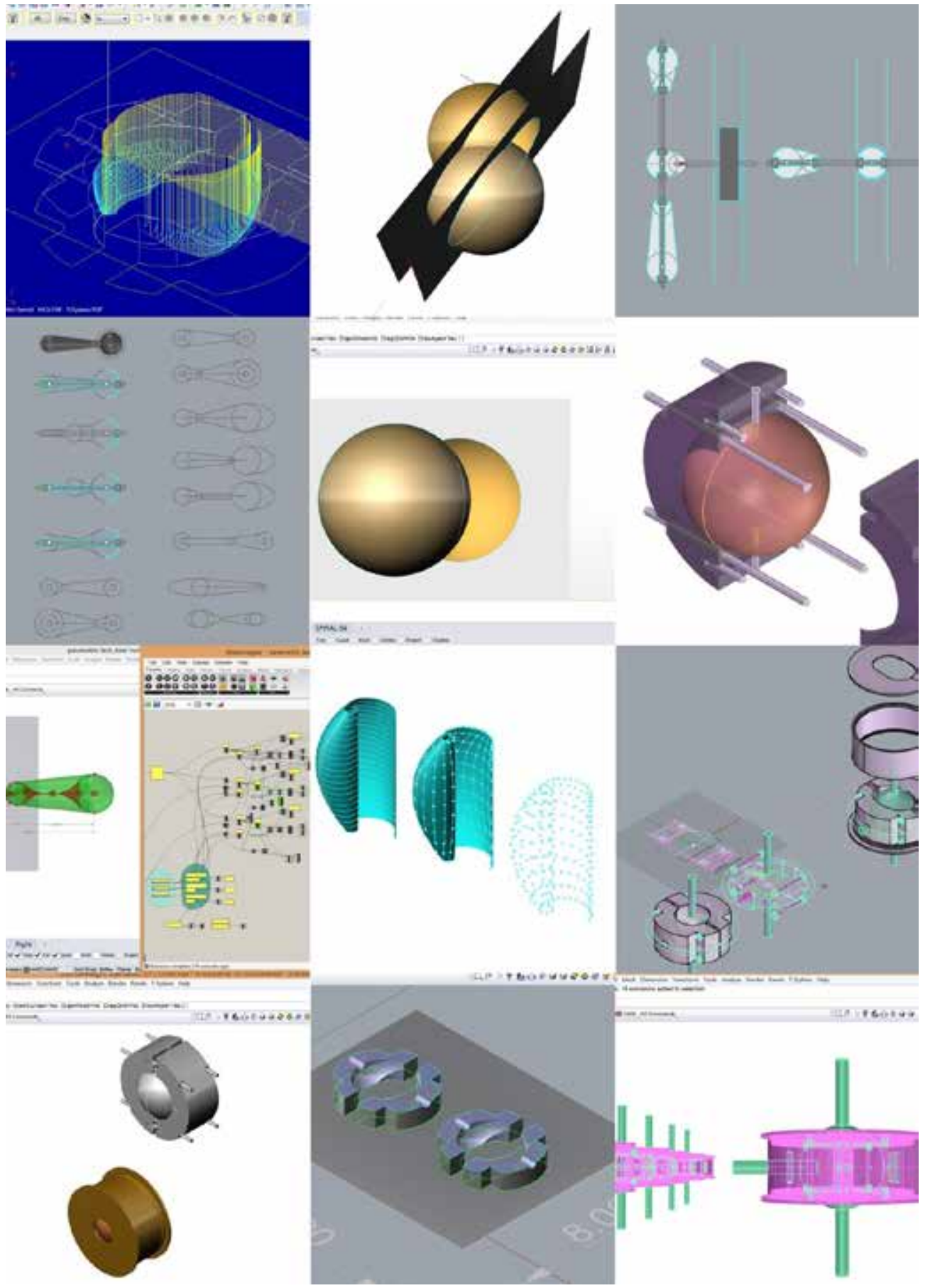

Figure 5: A moment without gravity for the sake of clarity. Numerous investigations progressed from physical material into digital development, often for increased precision and translation for machine language. Some ideas were digitally shaped, and material translations proved more poetic. Source: author. 


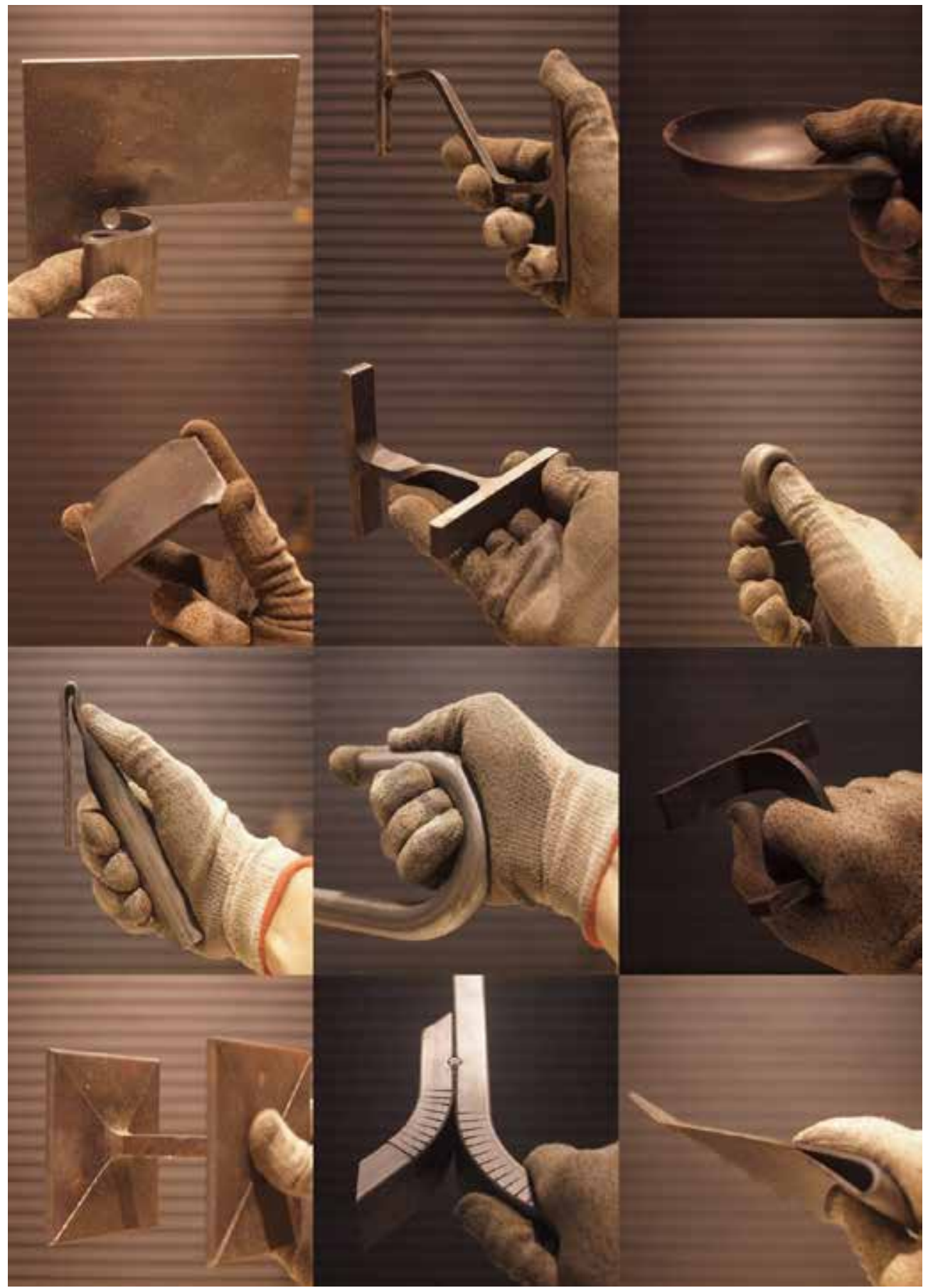

Figure 6: Thinking in steel. A study working with materials for simple manual tools: heat, hammer, anvil, and saw. Some sketches sought to transform recognisable architectural elements into discrete objects. Further steps are needed to address the completion and operational uses. Ideally their familiarity stays intact, with accustomed origins obscured. Source: author. 


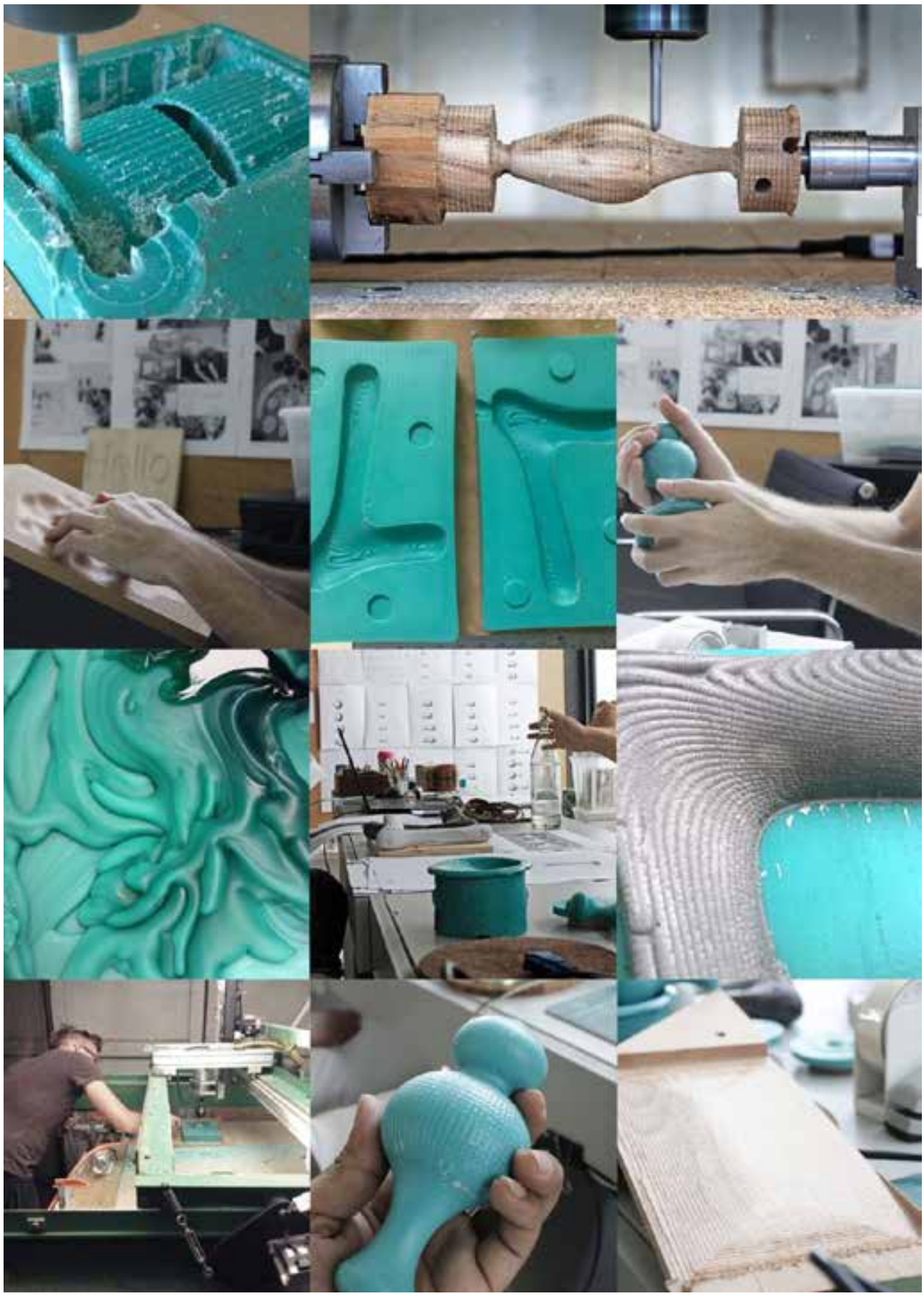

Figure 7: Letting the machines handle the material.

We expanded our studio's CNC capabilities to allow uninhibited experimentations. Moving fluidly from studio to workshop allows failure and discovery to overlap and materialise quicker. We machine directly into wax to create prototypes that can either be cast in metal, or cast aside. Source: author. 


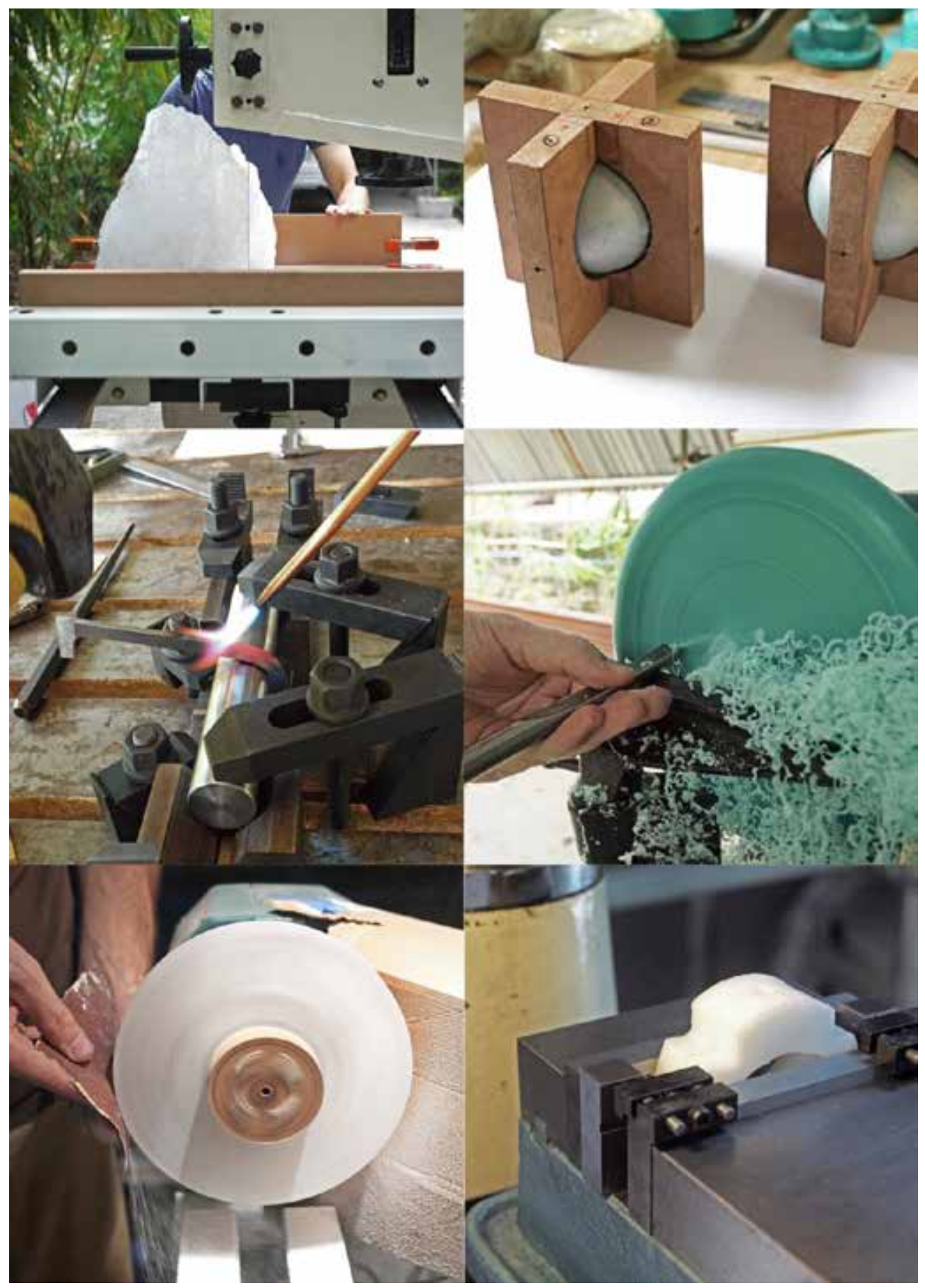

Figure 8: Sharpening tools and working materials.

We complete as much work as possible in our facilities. We collaborate when our skills or tools have reached capacity. Having an intimate relationship with the successes and failures of our ideas tunes our ears to the desires and fears of the material we work with. Source: author. 

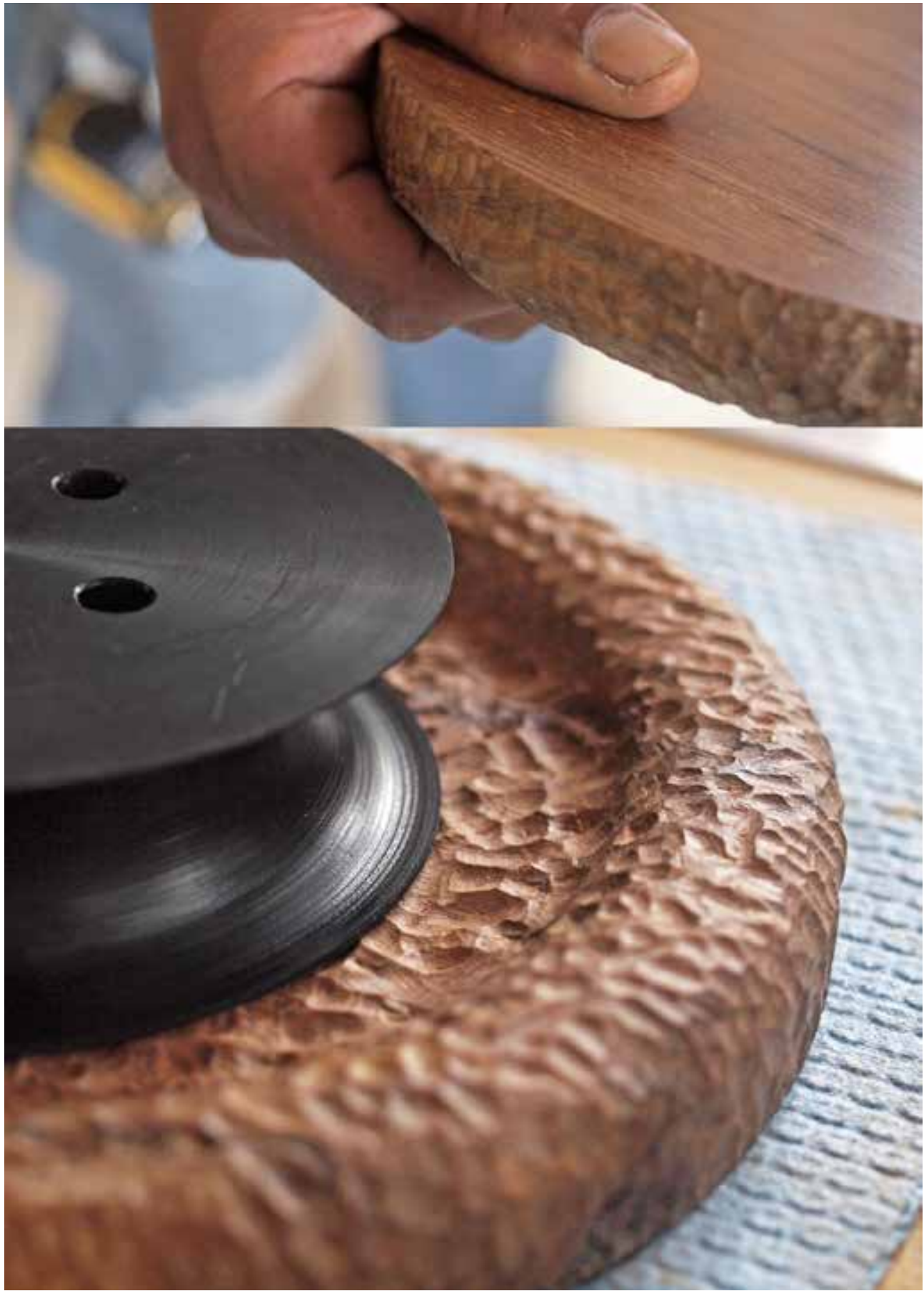

Figure 9: Traces of wear. Texture detail of hand chiselled back lip and hand polished front surface of a teak door handle. Source: author. 


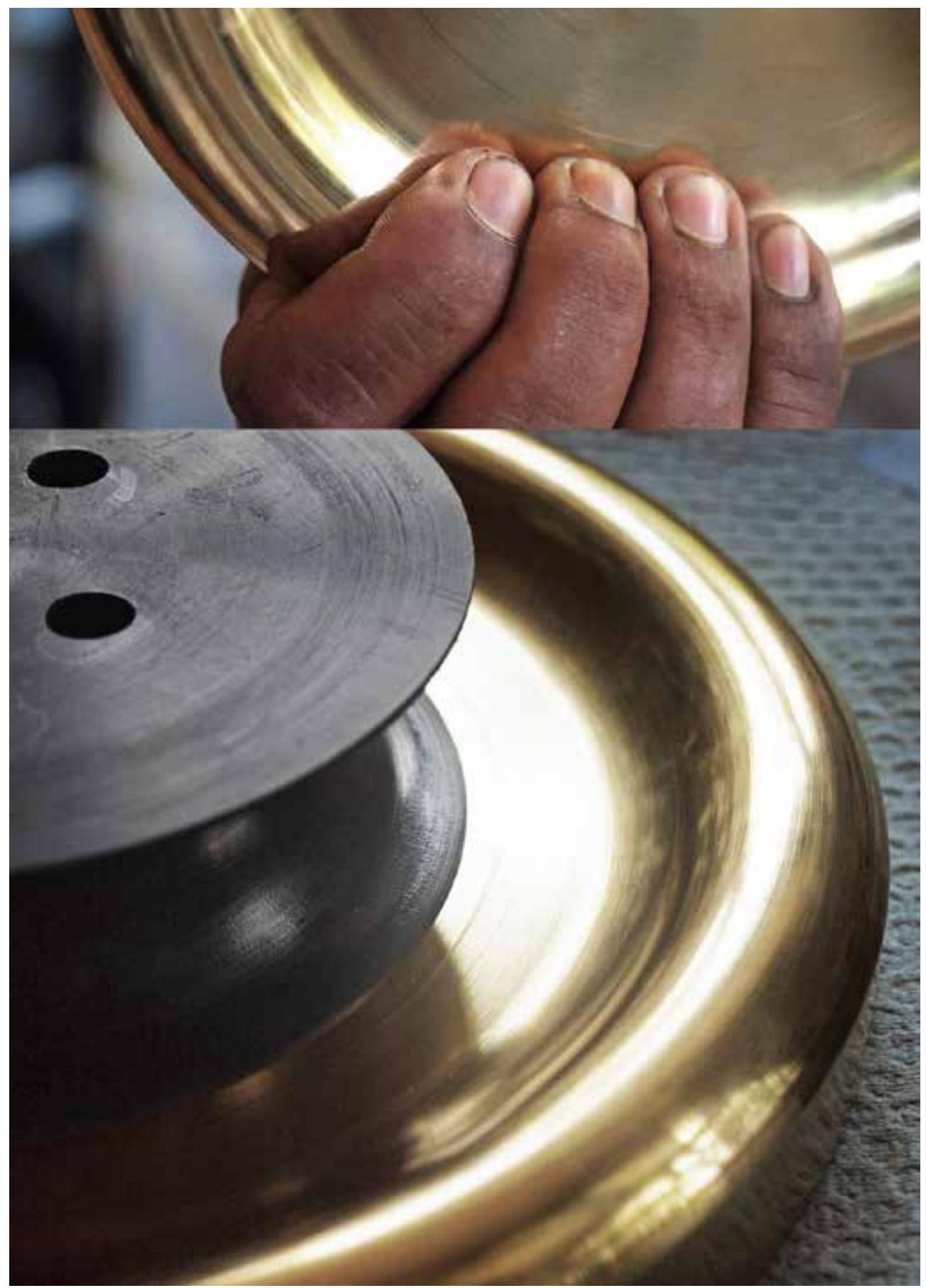

Figure 10: Traces of wear. A backside lip for fingers on a brass door handle. Source: author. 


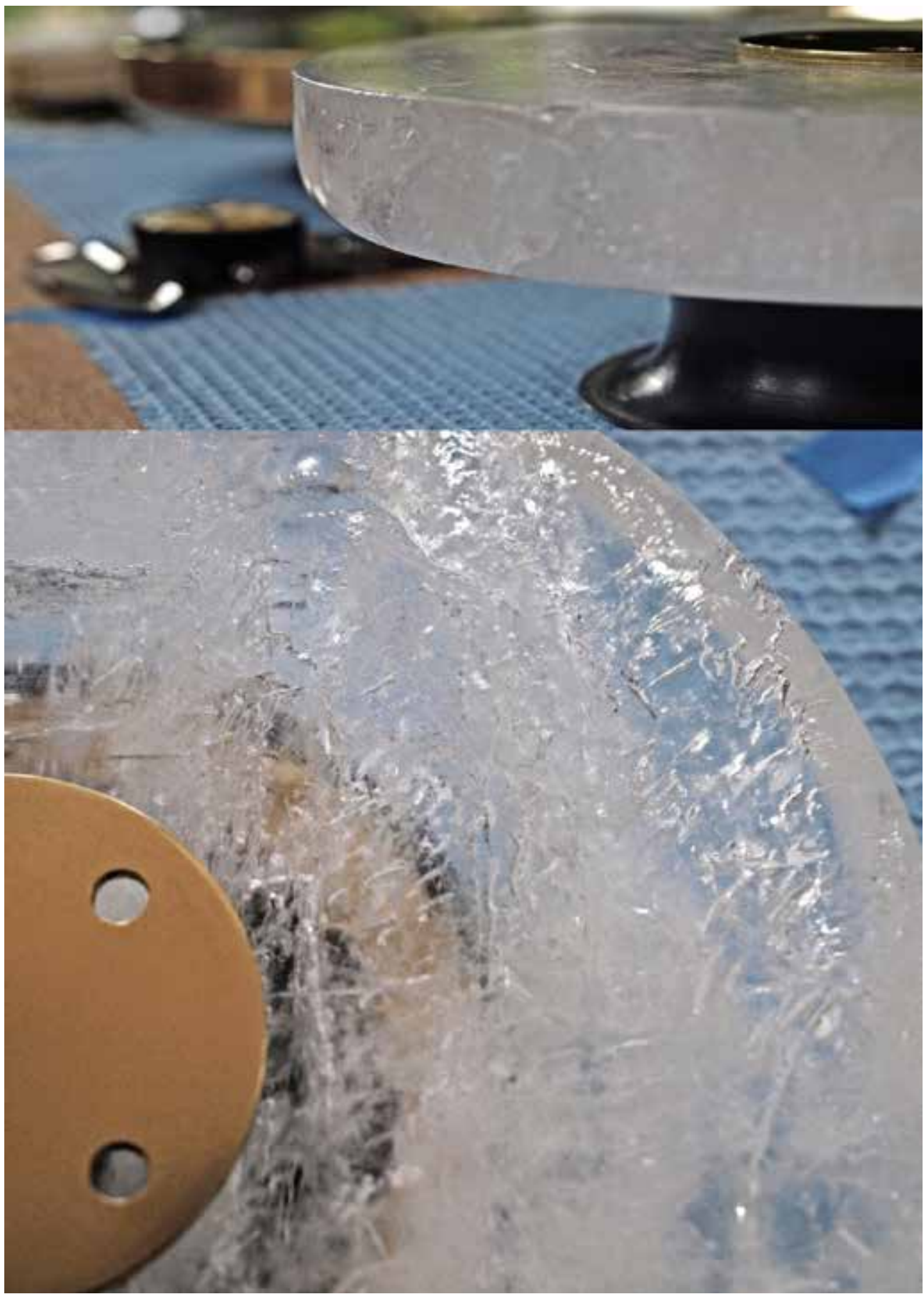

Figure 11: Traces of wear. Brass and acetal thermoplastic details on a crystal potassium alum door handle. Subjected to use, the crystal erodes over time revealing the pattern of use whilst fulfilling a simple sanitation role in the process. Source: author. 


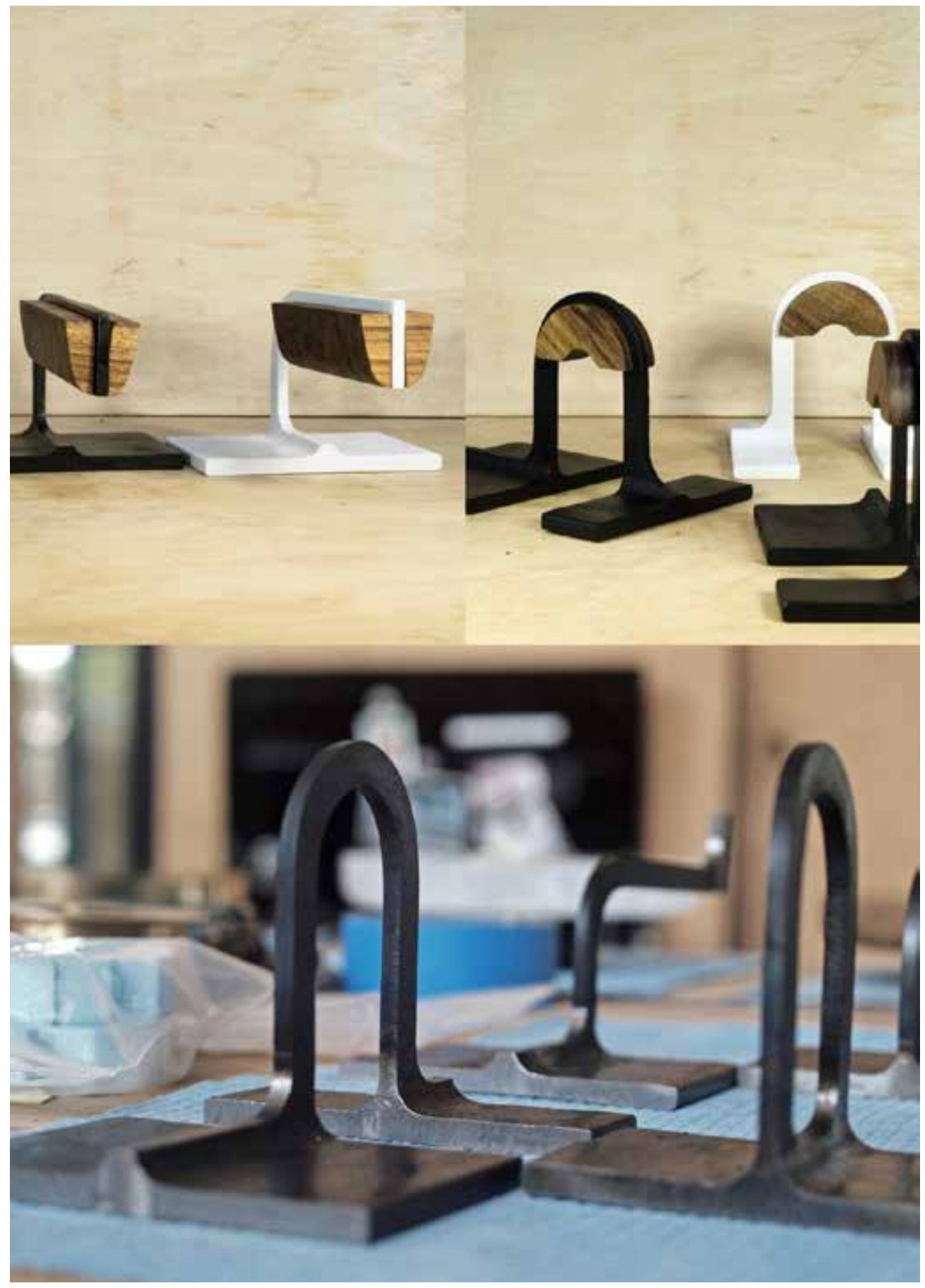

Figure 12: Fragments of architecture. Extensively milled wide flange beams result in delicate forms, belying their industrial origins. Discolouration shows heat-bending boundaries. Source: author. 


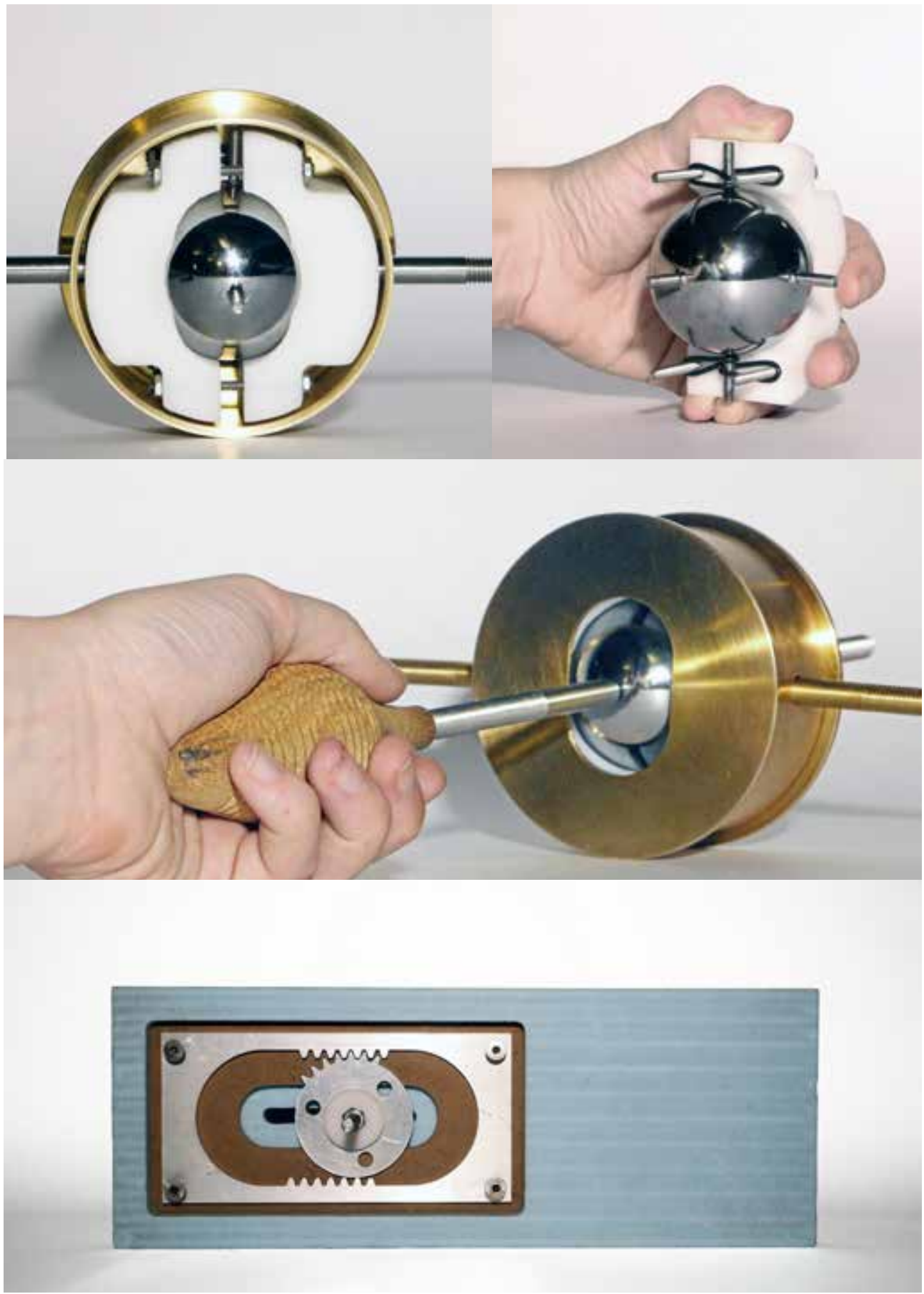

Figure 13: Operational expectations. Interior details of the spherical handshake and the mangle-rack latch, mechanisms which facilitate a multifaceted engagement while granting passage. Source: author.
Figure 14 (right): A single table for diverse ideas. Moving forward with multiple, concurrent designs allows parallel ideas to influence each other during the act of making. Source: author. 


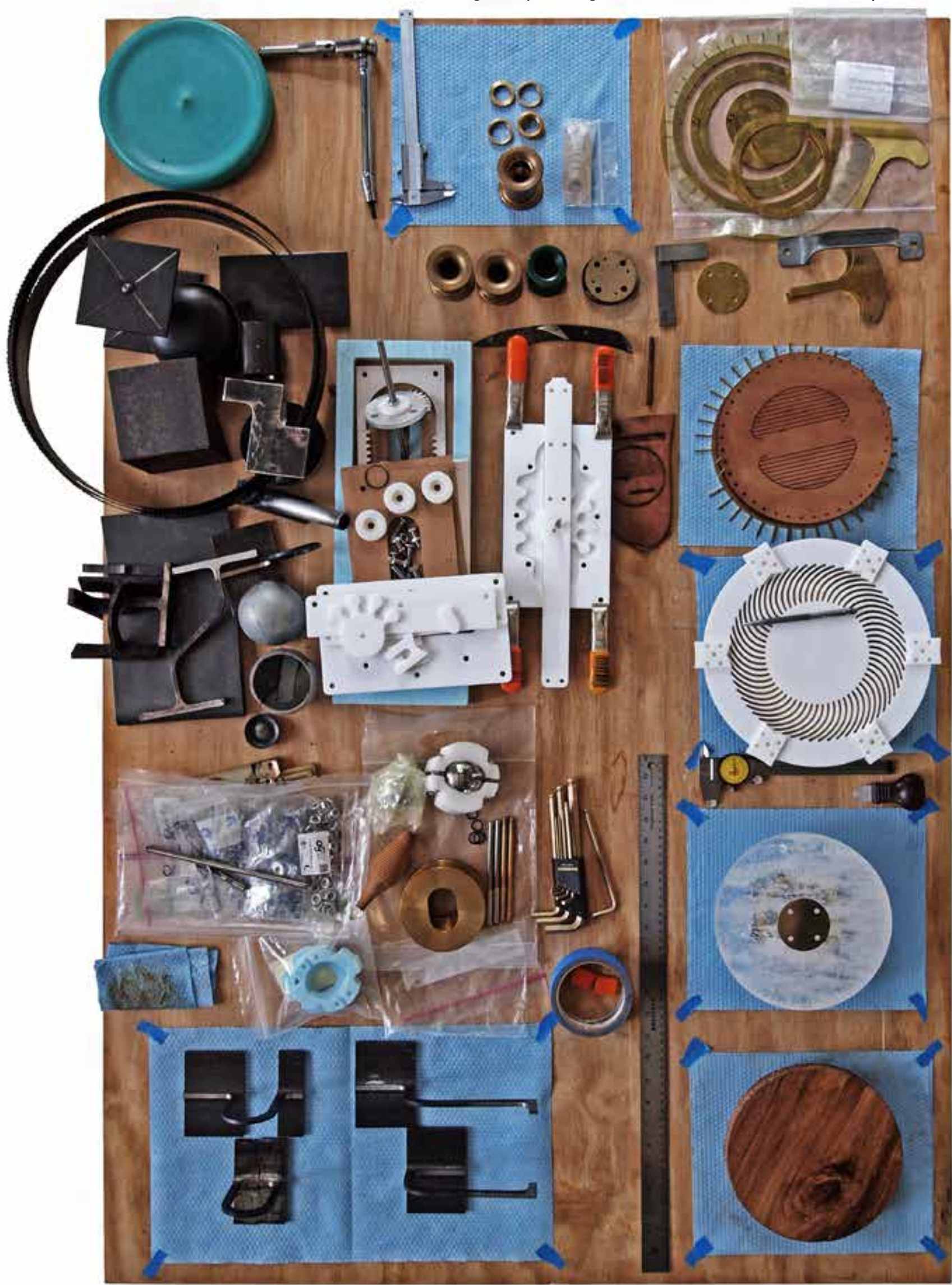




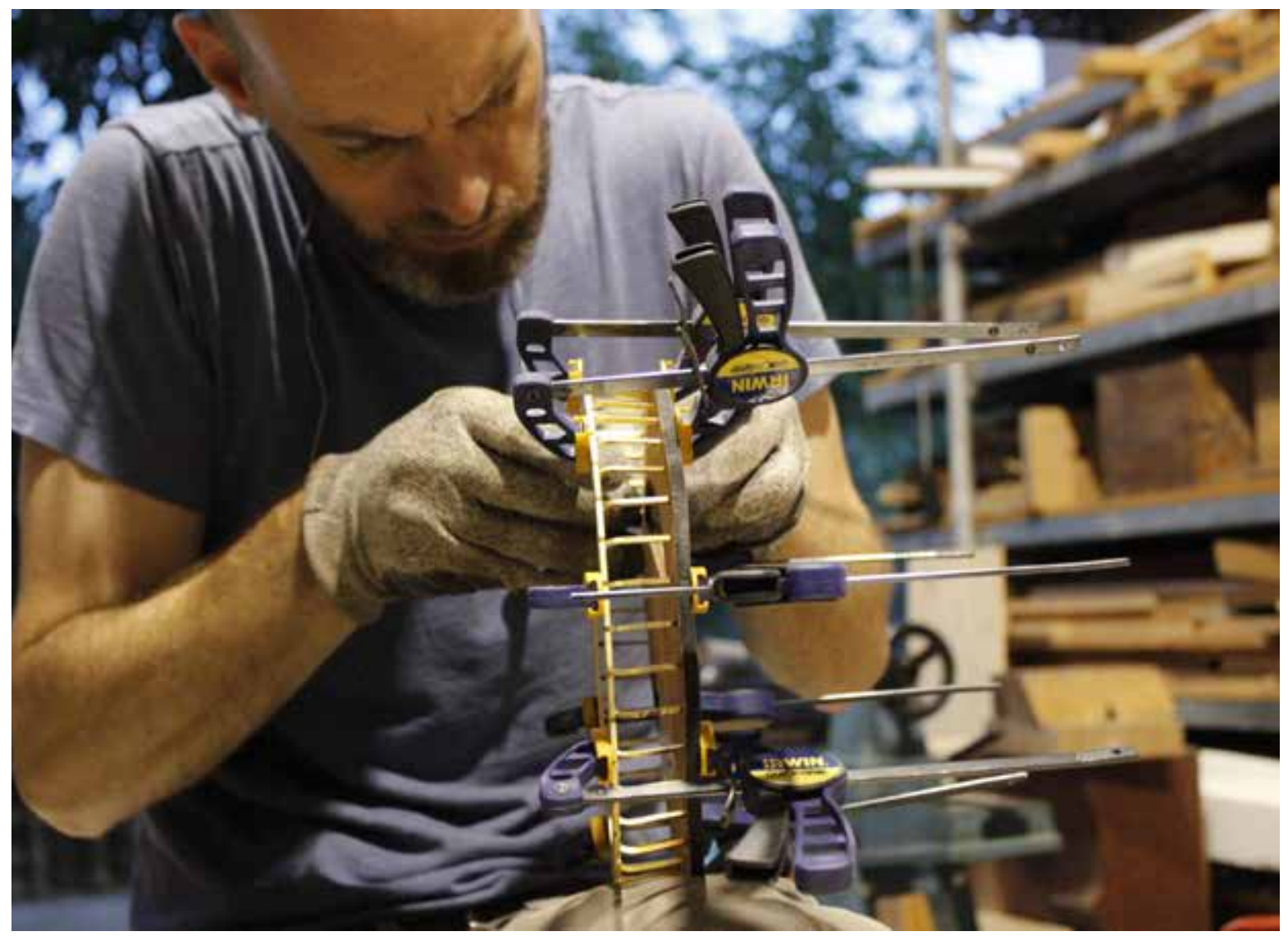

Figure 15: Coaxing together a brass stretcher plate and a buffalo leather diaphragm. Both pieces are strategically laser cut to allow certain areas to exhibit weakness, facilitating assembly, and other areas cut to gain strength from changes in geometry. With time the entire assembly will slowly settle into a graceful form derived from repetitive use as the leather stretches against the brass. Both items can be seen in their assembled state in the upper right side of Figure 14. Source: author. 


\section{Bibliography}

Cadwell, Mike. 2007. Strange Details. Cambridge, MA: MIT Press.

Crawford, Matthew B. 2010. Shop Class as Soulcraft: an Inquiry into the Value of Work. New York, NY: Penguin Books.

Pallasmaa, Juhani. 2014. The Eyes of the Skin: Architecture and the Senses. Chichester, UK: Wiley.

Pallasmaa, Juhani. 2015. The Thinking Hand: Existential and Embodied Wisdom in Architecture. Chichester, UK: Wiley.

Ruskin, John. 1853. The Stones of Venice, Vol. II. London, UK: Smith, Elder and Co.

Sennett, Richard. 2009. The Craftsman. London, UK: Penguin Books.

Sheil, Bob. 2005. Design Through Making. Chichester, UK: Wiley-Academy.

\section{Bio}

David Schafer is an architect and fabricator based in Bangkok, Thailand since 2009. Originally from California, he first explored architecture at the University of Arizona. He earned his architecture license from the State of California, and then returned to academics to study a more intimate scale of making. At Cranbrook Academy of Art, he formulated the approach that would lead him and his late partner, Im Sarasalin Schafer, to establish Studiomake. This practice maintains that innate understanding of our environment is rooted in intimate scales of interaction. In their studio these tactile moments develop from fluid, recurrent shifts between the act of design and the performance of construction. Working in full scale and real time the team of architects and craftsmen explore the overlapping realms of architecture, interiors, furniture, and object design. 